\title{
Bio-diatomite dynamic membrane reactor for micro-polluted surface water treatment
}

\author{
Huaqiang $\mathrm{Chu}^{a}$, Dawen $\mathrm{Cao}^{b}$, Bingzhi Dong ${ }^{\mathrm{c}, *}$, Zhimin Qiang ${ }^{d}$ \\ ${ }^{a}$ School of Environmental Science and Engineering, Tongji University, Shanghai 200092, China \\ ${ }^{b}$ National Engineering Research Centre for Urban Pollution Control, Shanghai 200092, China \\ ' State Key Laboratory of Pollution Control and Resource Reuse, Tongji University, Shanghai 200092, China \\ ${ }^{d}$ Research Center for Eco-Environmental Sciences, Chinese Academy of Sciences, Beijing 100085, China
}

\section{A R T I C L E I N F O}

\section{Article history:}

Received 18 June 2009

Received in revised form

1 November 2009

Accepted 4 November 2009

Available online 11 November 2009

\section{Keywords:}

Bio-diatomite dynamic

membrane reactor

Micro-polluted surface water

Dissolved organic materials

Biodegradation

Drinking water treatment

\begin{abstract}
A B S T R A C T
This work investigated the feasibility of treating micro-polluted surface water for drinking water production with a bio-diatomite dynamic membrane reactor (BDDMR) at lab-scale in continuous-flow mode. Results indicate that the BDDMR was effective in removing $\mathrm{COD}_{\mathrm{Mn}}$, DOC, $\mathrm{UV}_{254}, \mathrm{NH}_{3}-\mathrm{N}$ and trihalomethanes' formation potential (THMFP) at a hydraulic retention time (HRT) of $3.5 \mathrm{~h}$ due to its high concentrations of mixed liquor suspended solids (MLSS) and mixed liquor volatile suspended solids (MLVSS). The removal of pollutants was mainly ascribed to microbial degradation in BDDMR because the dynamic membrane alone was much less effective in pollutant removal. Though the diatomite particles $(5-20 \mu \mathrm{m})$ were much smaller in size than the aperture of the stainless steel support mesh $(74 \mu \mathrm{m})$, microorganisms and their extracellular polymer substances could bind these particles tightly to form bio-diatomite particles which were completely retained by the support mesh. The analysis of molecular weight (MW) distribution by gel permeation chromatography (GPC) shows that the BDDMR could effectively remove the hydrophilic fraction of dissolved organic materials present in the raw water.
\end{abstract}

(c) 2009 Elsevier Ltd. All rights reserved.

\section{Introduction}

The dynamic membrane technology for wastewater treatment has gained great attention in recent years due to its cost-effective membrane module, reduced energy consumption and high effluent quality. Therefore, it is considered as a substitute to the conventional membrane bioreactor (MBR) (Kiso et al., 2004; Gander et al., 2000; Chu and Li, 2006). Dynamic membrane is formed on the underlying support mesh when filtering a solution containing fine particles, thus is also called secondary membrane (Kuberkar and Davis, 2000). The dynamic membrane formed on the relatively large-pore mesh increases the intrinsic membrane retention capacity (Alavi Moghaddam et al., 2002a,b), leading to a high solid-liquid separation efficiency and a high filtration flux (Seo et al., 2002, 2007; Fuchs et al., 2005). Dynamic membrane is also more convenient to clean than membrane reactor. Tap water backwash, air backwash or mechanical brushing can readily clean the dynamic membrane without using any chemical reagents (Al-Malack and Anderson, 1997; Fan and Huang, 2002; Ye et al., 2006).

It was reported that diatomite particles could be used as carriers for microorganisms (Zhao et al., 2006). The microbial colonies can form zoogloeas on diatomite particles through microbial capsules and surface mucus and bio-diatomite is thus named. The bio-diatomite reactor, which combines

\footnotetext{
* Corresponding author. Tel.: +86 21 65982691; fax: +86 2165982313.

E-mail addresses: chq123zl@hotmail.com (H. Chu), dbz77@tongji.edu.cn (B. Dong). 0043-1354/\$ - see front matter (c) 2009 Elsevier Ltd. All rights reserved. doi:10.1016/j.watres.2009.11.006
} 
bio-diatomite together with anoxic and/or aerobic processes, has become a new wastewater treatment technology (Jin et al., 2005). The bio-diatomite reactor with an MLSS concentration of usually above $10,000 \mathrm{mg} / \mathrm{L}$ yields a high and stable efficiency if used for municipal wastewater treatment.

Recently, a BDDMR has been developed for municipal wastewater treatment (Chu et al., 2008). The BDDMR could effectively remove chemical oxygen demand (COD), $\mathrm{NH}_{3}-\mathrm{N}$ and total nitrogen (TN), and exhibited the advantages of effective suspended solids (SS) interception, short precoating time, high filtration flux, and easy backwashing. Since diatomite has long been used as a filtration medium in water plants and much research has been conducted on diatomite in water supply (Langé et al., 1986; Ongerth and Hutton, 2001), the BDDMR may also be applied to drinking water treatment.

In China, many water resources have been contaminated to some extent, which threatens the drinking water quality. The primary pollutants include $\mathrm{NH}_{3}-\mathrm{N}$ and dissolved organic materials which are particularly composed of non-acidic hydrophilic fraction (Xu et al., 2007). Though MBR is quite efficient in removing these pollutants, the relatively expensive operation cost as well as fouling problem severely limits its practical application. Therefore, there is an urgent need to develop a new treatment technology for high-quality drinking water production from micro-polluted surface water. This paper, therefore, was to assess the effectiveness of the BDDMR for drinking water treatment.

\section{Materials and methods}

\subsection{BDDMR process}

A lab-scale continuous-flow BDDMR was established for experimental study, as shown in Fig. 1. The BDDMR process consisted of two parts, i.e., an aerobic tank in which a dynamic membrane filter was situated and an automatic control system. The total effective volume of the aerobic tank and the dynamic membrane filter was $8.1 \mathrm{~L}$. Stainless steel mesh $(20 \mathrm{~cm} \times 11.5 \mathrm{~cm})$ with an equivalent aperture of $74 \mu \mathrm{m}$ was used as support module for the bio-diatomite dynamic membrane (BDDM). It was submerged in the aerobic tank with a double-sided effective filtration area of $0.046 \mathrm{~m}^{2}$.

\subsection{Experimental procedures}

Experiments were carried out from August 2008 to January 2009. The raw surface water was collected from Sanhaowu stream on Tongji campus. Its major physicochemical characteristics are summarized in Table 1 . The continuous-flow biofilm mode was used to form the bio-diatomite in the startup stage. As indicated in Table 1, the micro-polluted Sanhaowu stream water was dystrophic for microbial growth due to the lack of nitrogen (i.e., $0.41-2.52 \mathrm{mg} / \mathrm{L} \mathrm{NH}_{3}-\mathrm{N}$ ) and organic

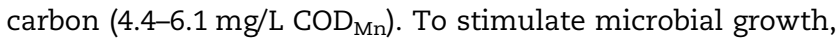
glucose was externally added to the influent to increase $\mathrm{COD}_{\mathrm{Mn}}$ to about $10 \mathrm{mg} / \mathrm{L}$ during the initial $3 \mathrm{~d}$ of the bioreactor start-up stage. Ammonium sulfate was added if the $\mathrm{NH}_{3}-\mathrm{N}$ concentration in raw water was below $1.0 \mathrm{mg} / \mathrm{L}$ so as to maintain $1.0-3.0 \mathrm{mg} / \mathrm{L} \mathrm{NH}_{3}-\mathrm{N}$ in the influent. Diatomite particles with an equivalent diameter of $5-20 \mu \mathrm{m}$ were continuously supplied to the bioreactor during the cultivation stage to reach a concentration of about $8000 \mathrm{mg} / \mathrm{L}$ in the aerobic tank. The bioreactor was continuously operated by feeding the raw water with a peristaltic pump and withdrawing the effluent with a frequency converter pump. The bio-diatomite was matured after the bioreactor had run for $20 \mathrm{~d}$ in summer at a temperature of $27-29^{\circ} \mathrm{C}$. The concentrations of MLSS and MLVSS in the BDDMR were maintained at about $12,000 \mathrm{mg} / \mathrm{L}$ and $3500-4000 \mathrm{mg} / \mathrm{L}$, respectively. The average sludge age was $40 \mathrm{~d}$ with $200 \mathrm{~mL}$ of excess sludge discharged daily. The feeding rate of diatomite was properly adjusted according to the excess sludge quantity and the real-time MLSS and MLVSS concentrations.

The BDDM flux was set at $50 \mathrm{~L} / \mathrm{m}^{2} \mathrm{~h}$, corresponding to an HRT of $3.5 \mathrm{~h}$. A high-precision vacuum pressure gauge was installed on the effluent pipe to measure the suction pressure (i.e., operation pressure) which was used to calculate the trans-membrane pressure (TMP). The operation period of BDDM involved three stages, i.e., precoating, filtration and backwash. In the precoating stage, the bio-diatomite mixed liquor was continuously recirculated by the frequency converter pump until the BDDM was formed on the surface of the support mesh. In the filtration stage, a constant flux of $50 \mathrm{~L} / \mathrm{m}^{2} \mathrm{~h}$ was applied and the thickness of BDDM showed a continuous increase, which resulted in the rising of filtration resistance. The filtration was stopped once the operation

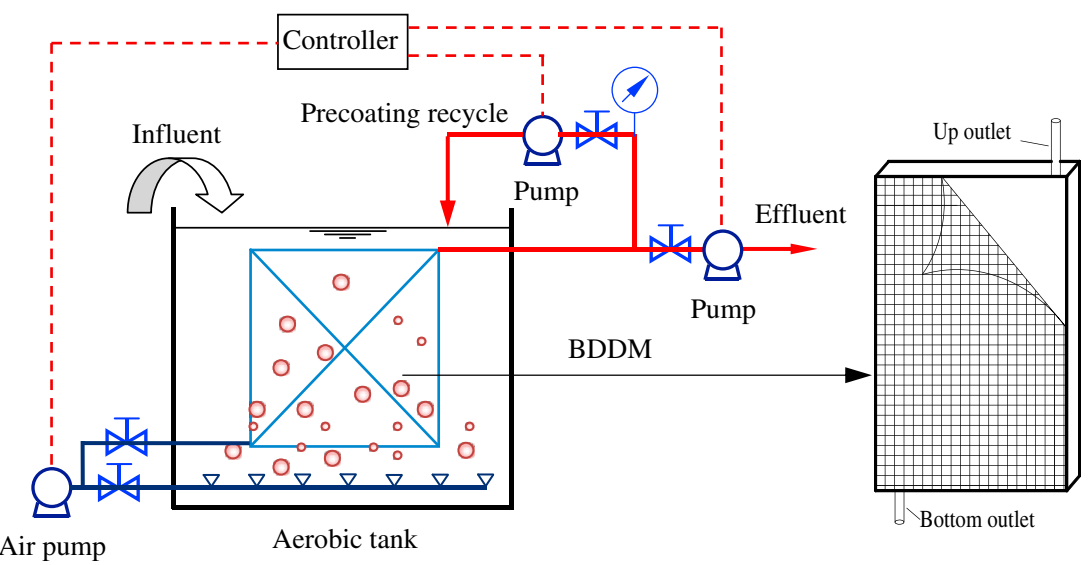

Fig. 1 - Schematic diagram of the BDDMR process. 
Table 1 - Characteristics of raw water.

\begin{tabular}{|c|c|}
\hline Water quality parameters & Range \\
\hline Temperature $\left({ }^{\circ} \mathrm{C}\right)$ & $18.6-29.6$ \\
\hline $\mathrm{pH}$ & $6.92-7.83$ \\
\hline Turbidity (NTU) & $2.5-4.7$ \\
\hline $\mathrm{COD}_{\mathrm{Mn}}(\mathrm{mg} / \mathrm{L})$ & $4.4-6.1$ \\
\hline TOC (mg/L) & $2.3-3.2$ \\
\hline $\mathrm{UV}_{254}\left(\mathrm{~cm}^{-1}\right)$ & $0.061-0.084$ \\
\hline $\mathrm{NH}_{3}-\mathrm{N}(\mathrm{mg} / \mathrm{L})$ & $0.41-2.52$ \\
\hline
\end{tabular}

pressure reached $40 \mathrm{kPa}$ and then backwash was started. To improve the membrane recovery, on-line backwash was performed with air through the bottom outlet of the membrane module using an air pump (Maple Mini Air Compressor, China).

\subsection{Analytical methods}

Turbidity, $\mathrm{COD}_{\mathrm{Mn}}$, and $\mathrm{NH}_{3}-\mathrm{N}$ were analyzed according to Chinese State Environmental Protection Agency (SEPA) Standard Methods (Chinese SEPA, 2002). Turbidity was measured by a turbidity meter (Model $2100 \mathrm{~N}$, Hach, USA). $\mathrm{NH}_{3}-\mathrm{N}$ was analyzed using the Nessler reagent method with absorbance measured by a spectrometer (Model Gold Spectrumlab 53, Lingguang, China). UV $_{254}$ was determined by a UV2550 spectrophotometer (Shimadzu, Japan) in a quartz cell with $1-\mathrm{cm}$ optical path length.

The dissolved oxygen (DO) in the bioreactor was measured with a DO meter (Model HQ10, Hach, USA). The membrane flux was measured by the volumetric method with a graduated cylinder. Dissolved organic carbon (DOC) of the influent, bioreactor mixed liquor (pre-centrifuged at $3000 \mathrm{rpm}$ for $5 \mathrm{~min}$ ) and effluent were measured after filtration through $0.45-\mu \mathrm{m}$ membrane by a TOC analyzer (TOC-VCPH, Shimadzu, Japan). MLSS was quantified by its ash content after drying the mixed liquor sample at $105^{\circ} \mathrm{C}$ for $24 \mathrm{~h}$ and further calcining at $600{ }^{\circ} \mathrm{C}$ for $1 \mathrm{~h}$ (He, 1998). MLVSS was calculated afterwards.

Trihalomethanes' formation potential (THMFP) was determined following USEPA Method 551.1 with gas chromatography-electron capture detector (GC-ECD) (Agilent $6890 \mathrm{~N}$, USA) equipped with a capillary column $(30.0 \mathrm{~m} \times$ $0.32 \mathrm{~mm} \times 0.25 \mu \mathrm{m}, \quad$ HP-5, Agilent J\&W, USA). Molecular weight (MW) distribution was measured with the GPC method on a high performance liquid chromatography (LC-10AD, Shimadzu, Japan) system coupled with an SPD-20A UV detector and a TSK-GEL G3000PWXL column $(7.8 \mathrm{~mm} \times$ $300 \mathrm{~mm})$. Anhydrous sodium sulfate $(0.05 \mathrm{M})$ was used as the isocratic mobile phase. The separated compounds were detected by UV absorbance at $254 \mathrm{~nm}$. The MW distribution pattern was derived by calibration with poly-styrene sulphonate MW standards of $14,7.5,4.3,1.4,0.7,0.5$ and $0.21 \mathrm{kDa}$. During the study, a piece of BDDM attached to the stainless steel support mesh was cut from the membrane module. After dehydrating by natural evaporation for $48 \mathrm{~h}$ and coating with gold using a sputter coater, the sample was examined by scanning electron microscopy (SEM) (XL-30ESEM, Philips, Holland).

The XAD resin method was used to fractionate the dissolved organic matter in each MW range of raw water following the procedure proposed by Thurman and Malcolm (1981). Adsorbent resins (Amberlite XAD-8 and XAD-4) were used to separate the dissolved organic matter into hydrophobic (HPO), transphilic (TPI) and hydrophilic (HPI) fractions to reveal the distribution pattern of organic substances based on water affinity. These fractions were expressed in terms of DOC percentage.

\section{Results and discussion}

\subsection{BDDM precoating and operation flux}

Before normal filtration, the precoating of BDDM was carried out to form a bio-diatomite cake layer on the support mesh. Fig. $2 \mathrm{a}$ shows that the effluent SS concentration decreased quickly in the first $2 \mathrm{~min}$, and then dropped slowly to below the detection limit at about $15 \mathrm{~min}$. Correspondingly, the flux showed a similar change. At $30 \mathrm{~min}$, the effluent SS was almost zero and the corresponding flux was $68 \mathrm{~L} / \mathrm{m}^{2} \mathrm{~h}$, indicating the completion of BDDM precoating.

The change of TMP as a function of filtration time at various design fluxes is shown in Fig. $2 b$. Results indicate that the TMP rapidly increased with the increasing flux. The operation flux is correlated with the filtration time. A long filtration time can result in trouble in backwash when the residual bio-diatomite particles are over-compacted at the surface of the support mesh. Therefore, $50 \mathrm{~L} / \mathrm{m}^{2} \mathrm{~h}$ was selected as the operation flux in this study.

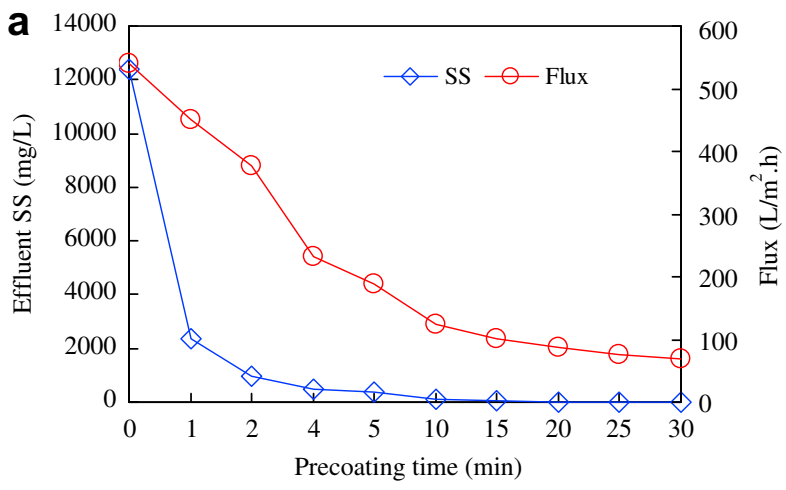

b

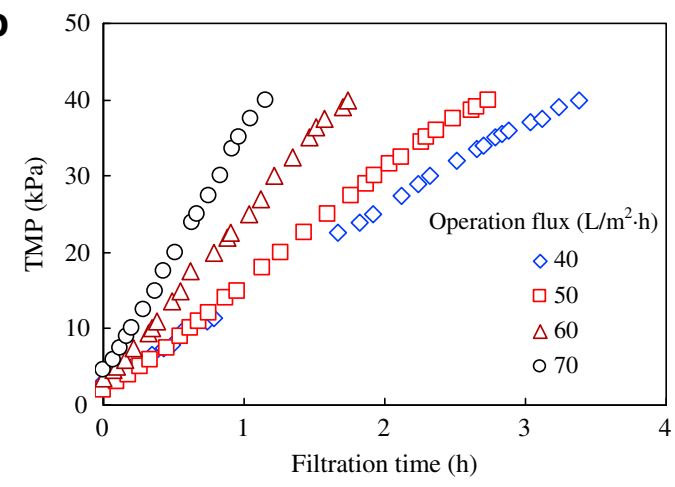

Fig. 2 - (a) Variations in flux and effluent SS with time in the precoating stage; and (b) operation pressure as a function of filtration time at different design fluxes. 


\subsection{Pollutants' removal}

Fig. 3 shows the removal efficiency of turbidity, $\mathrm{COD}_{\mathrm{Mn}}$, DOC, $\mathrm{UV}_{254}, \mathrm{NH}_{3}-\mathrm{N}$ and THMFP during the steady-state operation period ( $40 \mathrm{~d}$ ) of BDDMR.

Although the turbidity in the influent significantly fluctuated in the range of 2.5-4.7 NTU, a stable turbidity concentration of $0.26-0.43$ NTU in the effluent was observed, achieving a removal efficiency of approx. 90\% (Fig. 3a). The effluent turbidity concentration complies with the Chinese National Standards for Drinking Water Quality (CNSDWQ, GB5749-2006), i.e., below 1.0 NTU. Though this effluent turbidity was a little higher than that of MBR (Tian et al., 2008) due to a relatively larger pore size of the stainless steel support mesh, the BDDMR still exhibited a high efficiency for solid-liquid separation.

Fig. $3 \mathrm{~b}$ shows that as the $\mathrm{COD}_{\mathrm{Mn}}$ concentration in the influent varied from 4.4 to $6.1 \mathrm{mg} / \mathrm{L}$, a quite stable effluent concentration (i.e., $2.37 \mathrm{mg} / \mathrm{L}$ on average) could be achieved, corresponding to a removal efficiency of $54.7 \%$. The CNSDWQ (GB5749-2006) regulate a maximum contamination level (MCL) of $3.0 \mathrm{mg} / \mathrm{L}$ for $\mathrm{COD}_{\mathrm{Mn}}$. However, it is a great challenge to many water treatment plants. Nowadays many surface waters in China have a $\mathrm{COD}_{\mathrm{Mn}}$ concentration of $6.0 \mathrm{mg} / \mathrm{L}$ or even higher
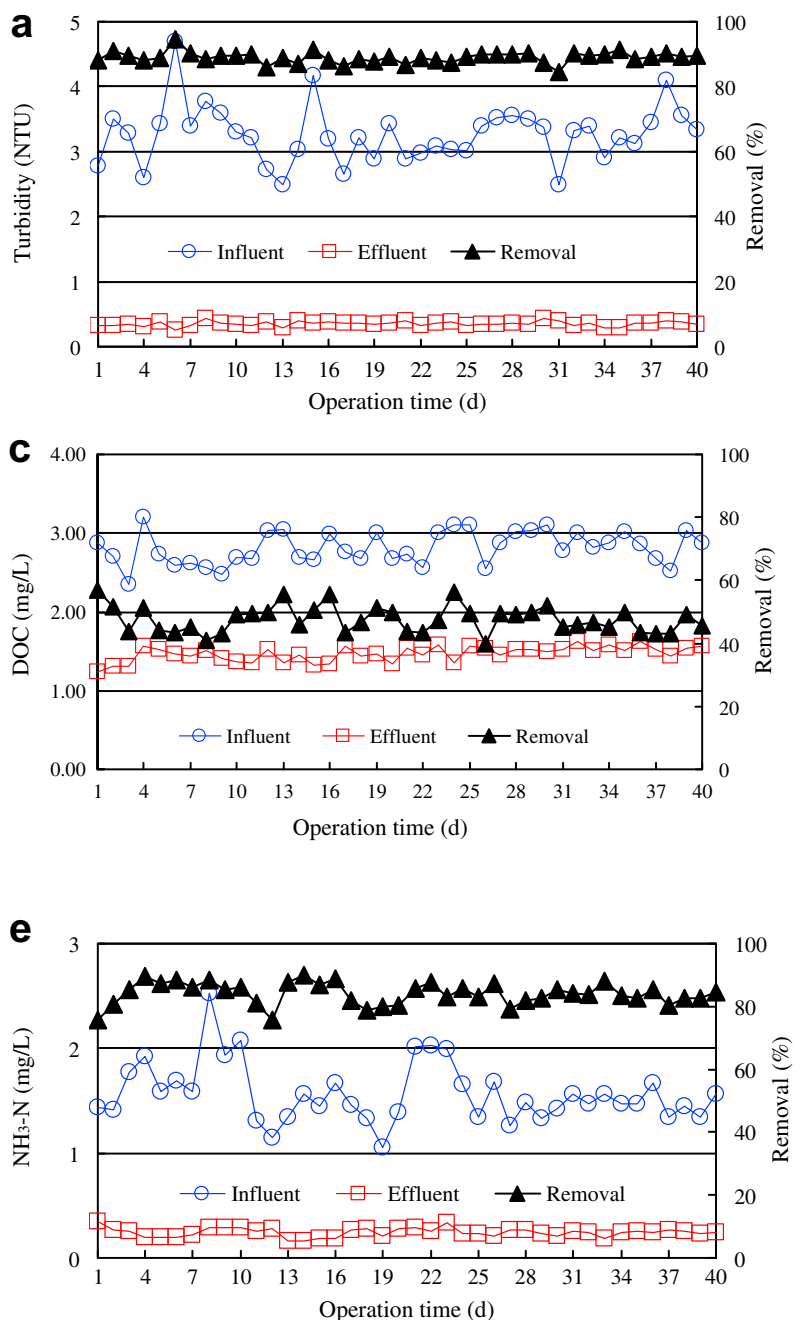

Fig. 3 - Removal of pollutants by BDDMR: (a) turbidity; (b) $\mathrm{COD}_{\mathrm{Mn}}$; (c) DOC; (d) $\mathrm{UV}_{254}$; (e) $\mathrm{NH}_{3}$-N; and (f) THMFP. due to pollution of municipal and industrial wastewaters caused by the rapid population growth and economic development in the past three decades. Therefore, the conventional process of coagulation/sedimentation/sand filtration, which is adopted by the majority of drinking water plants, can hardly reduce $\mathrm{COD}_{\mathrm{Mn}}$ to below $3.0 \mathrm{mg} / \mathrm{L}$. From the encouraging results of this work, BDDMR may be a promising technology to face this big challenge.

The removal efficiencies of DOC and $\mathrm{UV}_{254}$ by BDDMR are shown in Fig. $3 c$ and d. Results indicate that the BDDMR could remove DOC and $\mathrm{UV}_{254}$ by $47.6 \%$ and $53.7 \%$ on average, respectively. In our previous study, the same raw water was treated with enhanced coagulation and ultrafiltration. It was found that $\mathrm{UV}_{254}$ was only removed by $26 \%$ even after decreasing pH to 5.5 (Dong et al., 2006). Xu et al. (2007) reported that the coagulation/sedimentation/sand filtration process removed DOC and $\mathrm{UV}_{254}$ of Huangpu River water by $31.4 \%$ and $40.0 \%$, respectively. In addition, MBR could only remove $19.4 \%$ of DOC and $16.4 \%$ of $\mathrm{UV}_{254}$ when used for drinking water treatment at $670-740 \mathrm{mg} / \mathrm{L}$ MLSS and 180-230 mg/L MLVSS (Tian et al., 2008). It is thus clearly seen that the BDDMR has a better removal efficiency for DOC and $\mathrm{UV}_{254}$, which is primarily attributed to its high MLSS and MLVSS.
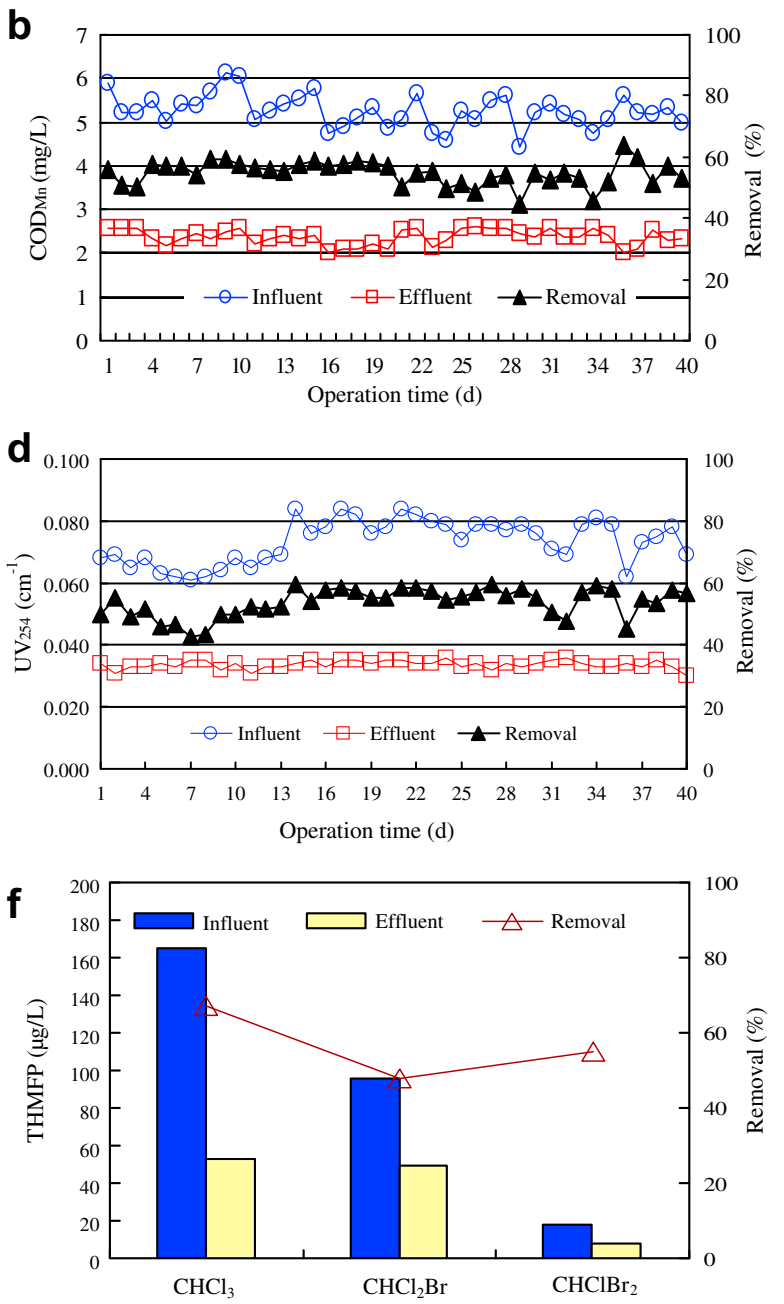
BDDMR could also remove $\mathrm{NH}_{3}-\mathrm{N}$ effectively, as shown in Fig. 3e. The removal efficiency of $\mathrm{NH}_{3}-\mathrm{N}$ reached as high as $75.5-89.8 \%$ and the effluent $\mathrm{NH}_{3}-\mathrm{N}$ concentration was always less than $0.35 \mathrm{mg} / \mathrm{L}$. Our previous study showed that the BDDM alone could achieve little $\mathrm{NH}_{3}-\mathrm{N}$ removal (Chu et al., 2008), thus $\mathrm{NH}_{3}-\mathrm{N}$ was mainly eliminated through microbial degradation in the bioreactor.

THMFP removal by BDDMR is shown in Fig. 3f. Three trihalomethanes were detected including $\mathrm{CHCl}_{3}, \mathrm{CHCl}_{2} \mathrm{Br}$ and $\mathrm{CHClBr}_{2}$ with an effluent concentration of 53,49 and $8 \mu \mathrm{g} / \mathrm{L}$, respectively, corresponding to a removal efficiency of $67 \%$, $48 \%$ and $55 \%$. Their effluent concentrations meet the requirement of the CNSDWQ (GB5749-2006) which regulate an MCL of 60,60 and $10 \mu \mathrm{g} / \mathrm{L}$ for $\mathrm{CHCl}_{3}, \mathrm{CHCl}_{2} \mathrm{Br}$ and $\mathrm{CHClBr}$, respectively. $\mathrm{CHBr}_{3}$ was not detected in either influent or effluent. These results indicate that THMFP could be removed by the BDDMR effectively. The removal of THMFP is closely associated with the removal of DOC. Since $47.6 \%$ of DOC was removed by the BDDMR (Fig. 3c), it is not surprising that THMFP could be eliminated notably. It was reported that THMFP was generated mostly from the $<1 \mathrm{kDa}$ fraction of dissolved organic materials (Xu et al., 2007). The later results of this study (Section 3.4) will show that BDDMR could completely eliminate the dissolved organic materials with MW less than $1 \mathrm{kDa}$.

The mechanisms contributing to the reduction of $\mathrm{COD}_{\mathrm{Mn}}$ and DOC in the BDDMR may include microbial degradation, membrane interception and bio-diatomite adsorption. To determine which mechanism mainly accounted for pollutants' removal, the dynamic membrane module was carefully taken out from the bioreactor and then submerged into another tank that was filled with the same raw water but contained little MLSS. The identical automatic control system was applied. The removal efficiencies of pollutants by the BDDM alone are shown in Fig. 4. Results indicate that $\mathrm{COD}_{\mathrm{Mn}}$, $\mathrm{NH}_{3}-\mathrm{N}, \mathrm{DOC}$ and $\mathrm{UV}_{254}$ were only removed by $8.7 \%, 5.4 \%, 8.9 \%$ and $10.3 \%$, respectively. It is seen that the BDDM alone was much less effective in removing pollutants. The major function of BDDM was to support the bio-diatomite cake layer and intercept SS. The removal of $\mathrm{COD}_{\mathrm{Mn}}, \mathrm{NH}_{4}-\mathrm{N}, \mathrm{DOC}$ and $\mathrm{UV}_{254}$ was thus mainly ascribed to the microbial degradation in the aerobic tank. During the experimental course of

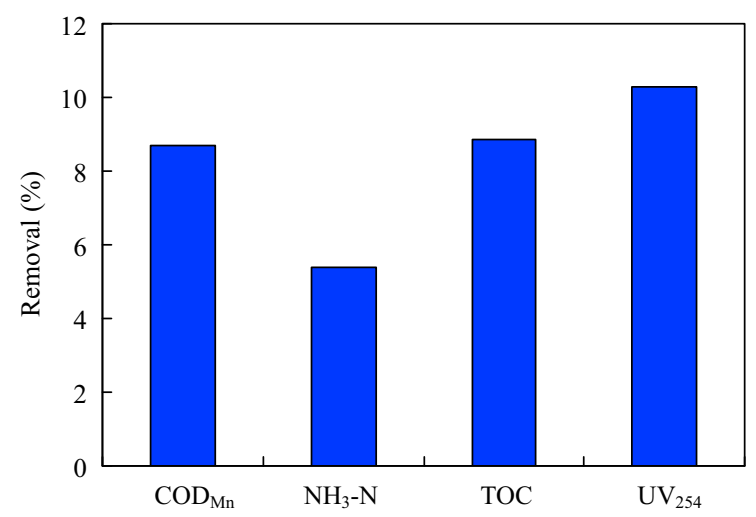

Fig. 4 - Removal of pollutants by BDDM alone. Data represent the average values of triplicate experiments.
BDDMR, the high MLSS (ca. 12,000 mg/L) and MLVSS (3500$4000 \mathrm{mg} / \mathrm{L}$ ) concentrations were maintained in the aerobic tank, thus the biodegradation of dissolved organic materials was enhanced.

\subsection{BDDM backwash}

As the TMP increased to $40 \mathrm{kPa}$, filtration was stopped and backwash was started. Our previous study has shown that on-line air backwash was highly effective in removing the cake layer on the support mesh (Chu et al., 2008), so it was also adopted in this study. The air backwash was run for $2 \mathrm{~s}$ at an air flux of $7.2 \mathrm{~L} / \mathrm{m}^{2} \mathrm{~s}$ (corresponding to an air pressure of $20 \mathrm{kPa}$ ). Comparing Fig. $5 \mathrm{a}$ with Fig. $5 \mathrm{~b}$, it is clearly seen that the cake layer was completely removed after air backwash. A clean surface of the support mesh was restored.

After filtration, the membrane module was taken out from the bioreactor and a piece of the bio-diatomite cake layer was carefully cut off to examine the morphological characteristics of the BDDM. Fig. 5c shows that the cake layer on the BDDM had a smooth surface and about 2-3 mm thickness. The cake layer was further examined by SEM. It is seen that its surface was a little rough under $100 \times$ magnification (Fig. 5d), and the diatomite was attached by microorganisms and extracellular polymer substances (Fig. 5e). Though the diatomite particles had a size $(5-20 \mu \mathrm{m})$ much smaller than the aperture of the stainless steel mesh $(74 \mu \mathrm{m})$, they were bound tightly through the microbial bridging action to form the BDDM.

\subsection{MW distribution of dissolved organic materials}

The MW distribution patterns of dissolved organic materials in the raw water, mixed liquor and effluent of the BDDMR were analyzed by the GPC method, as shown in Fig. 6a. Three major peak clusters in the MW order of $80 \mathrm{~K}, 800-2500$ and $37 \mathrm{Da}$ were observed in the raw water. Fig. $6 \mathrm{~b}$ shows the DOC percentages occupied by the HPO, TPI and HPI fractions in three MW ranges (i.e., $<1,1-10,>10 \mathrm{kDa}$ ) of the dissolved organic materials in raw water. It is seen that the hydrophilic fraction dominated in each MW range examined. Therefore, the three peak clusters mainly represent hydrophilic substances. In the mixed liquor, the first and third peak clusters completely disappeared and the second peak cluster notably decreased by about $40 \%$. Meanwhile, a new peak emerged at MW $170 \mathrm{Da}$. Further comparing the two spectra of mixed liquor and BDDM effluent, it is noted that the BDDM alone could hardly remove the MW 800-2500 Da peak cluster, but could remove the MW $170 \mathrm{Da}$ peak by about $60 \%$. This result implies: 1 ) both the MW $800-2500 \mathrm{Da}$ peak cluster and the MW 170 Da peak were able to penetrate the membrane; and 2) the former was non-biodegradable while the latter was partially biodegradable by the microorganisms residing in the BDDM. Moreover, the BDDMR could remove $47.6 \%$ of DOC in the raw water as described above. The removal percentage of dissolved organic materials reflected in Fig. 6a was approximately in agreement with the DOC removal. 

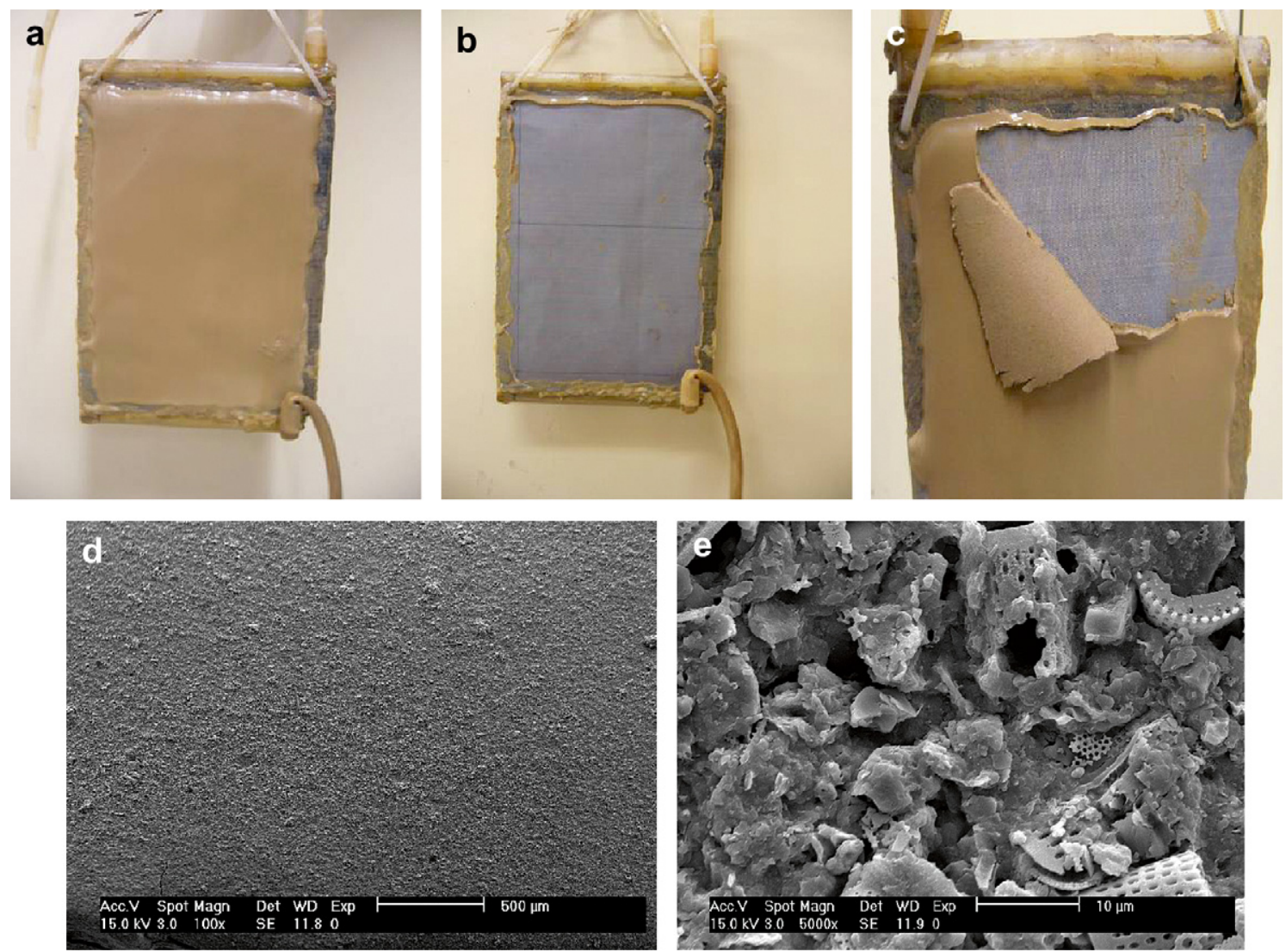

Fig. 5 - Pictures of BDDM: (a) before backwash; (b) after backwash; (c) cake layer thickness; (d) SEM (100×); and (e) SEM $(5000 \times)$.

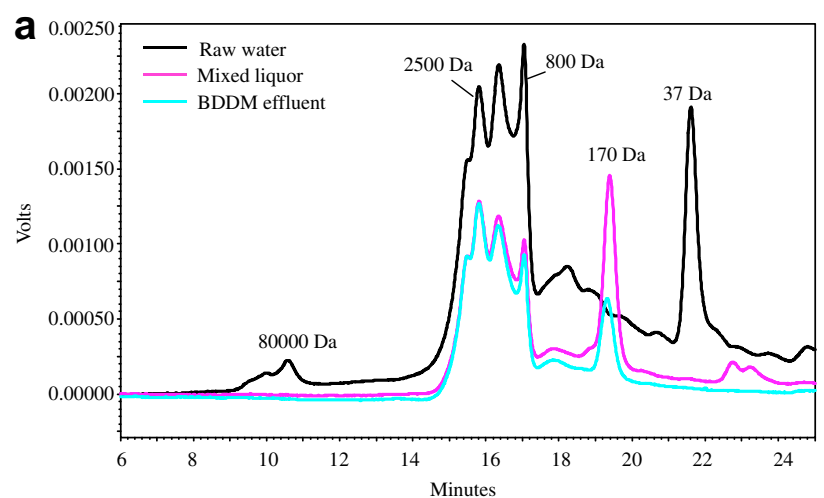

\section{Conclusions}

(1) A novel BDDMR process was developed to treat micropolluted surface water for drinking water production. Under the operational conditions of $3.5 \mathrm{~h} \mathrm{HRT}$ and $50 \mathrm{~L} / \mathrm{m}^{2} \mathrm{~h}$ constant flux, BDDMR could remove turbidity, $\mathrm{COD}_{\mathrm{Mn}}, \mathrm{DOC}$, $\mathrm{UV}_{254}, \mathrm{NH}_{3}-\mathrm{N}$ and THMFP effectively. The effluent quality could comply with the regulations of Chinese National Standards for Drinking Water Quality (GB5749-2006).

(2) The effectiveness of BDDMR on pollutants' removal was primarily ascribed to its high concentrations of MLSS $(12,000 \mathrm{mg} / \mathrm{L})$ and MLVSS $(3500-4000 \mathrm{mg} / \mathrm{L})$ in the aerobic tank which greatly enhanced biodegradation of dissolved organic materials present in raw water. The BDDM alone was much less effective in the removal of pollutants.

(3) Though diatomite particles were smaller in size than the aperture of the stainless steel mesh, microorganisms and their extracellular polymers bind the diatomite particles tightly to form the much bigger bio-diatomite particles which were completely retained by the support mesh, thus BDDM was established. The cake layer on the BDDM showed a smooth surface and a thickness of 2-3 $\mathrm{mm}$.

(4) The analysis of MW distribution shows that the BDDMR could completely remove the MW $80 \mathrm{~K}$ and $37 \mathrm{Da}$ peak clusters, and notably remove the MW 800-2500 Da peak cluster. Hydrophilic substances were a dominant fraction of the dissolved organic materials in the raw water. The BDDM alone could hardly remove the MW $800-2500 \mathrm{Da}$

Fig. 6 - (a) MW distribution patterns of raw water, mixed liquor and effluent of BDDMR; and (b) HPO, HPI and TPI fractions in each MW range of raw water (HPO: hydrophobic fraction; TPI: transphilic fraction; HPI: hydrophilic fraction). 
peak cluster, but could remove the MW $170 \mathrm{Da}$ peak by about $60 \%$.

\section{Acknowledgements}

This research was financially supported by the National Key Technologies R \& D Program (Project \# 2006BAJ08B02) and the Foundation of the State Key Laboratory of Pollution Control and Resource Reuse, China (PCRRK08006). We also appreciate the support from Tingyao Gao Environmental Science and Technology Development Foundation of Tongji University.

\section{R E F E R E N C E S}

Alavi Moghaddam, M.R., Satoh, H., Mino, T., 2002a. Performance of coarse pore filtration activated sludge system. Water Sci. Technol. 46 (11-12), 71-76.

Alavi Moghaddam, M.R., Satoh, H., Mino, T., 2002b. Effect of important operational parameters on performance of coarse pore filtration activated sludge process. Water Sci. Technol. 46 (9), 229-236.

Al-Malack, M.H., Anderson, G.K., 1997. Cleaning techniques of dynamic membranes. Sep. Purif. Technol. 12 (1), 25-33.

Chu, L., Li, S., 2006. Filtration capability and operational characteristics of dynamic membrane bioreactor for municipal wastewater treatment. Sep. Purif. Technol. 51 (1), 173-179.

Chu, H., Cao, D., Jin, W., Dong, B., 2008. Characteristics of bio-diatomite dynamic membrane process for municipal wastewater treatment. J. Membr. Sci. 325 (1), 271-276.

Chinese SEPA, 2002. Water and Wastewater Monitoring Methods, fourth ed. Chinese Environmental Science Publishing House, Beijing, China.

Dong, B.Z., Chen, Y., Gao, N.Y., Fan, J.C., 2006. Effect of pH on UF membrane fouling. Desalination 195, 201-208.

Fan, B., Huang, X., 2002. Characteristics of a self-forming dynamic membrane coupled with a bioreactor for municipal wastewater treatment. Environ. Sci. Technol. 36 (23), 5245-5251.

Fuchs, W., Resch, C., Kernstock, M., Mayer, M., Schoeberl, P., Braun, R., 2005. Influence of operational conditions on the performance of a mesh filter activated sludge process. Water Res. 39 (5), 803-810.

Gander, M., Jefferson, B., Judd, S., 2000. Aerobic MBRs for domestic wastewater treatment: a review with cost considerations. Sep. Purif. Technol. 18 (2), 119-130.

He, Y.L., 1998. Anaerobic Biological Treatment of Wastewater. China Light Industry Press, Beijing, China.

Jin, W., Zhao, Y.-P., Xu, Z.-X., Gao, T.-Y., 2005. Treatment of municipal wastewater using combined bio-diatomaceous earth. J. Tongji Univ. (Nat. Sci.) 33 (12), 1626-1629 (in Chinese).

Kiso, Y., Jung, Y.-J., Ichinari, T., Park, M., Kitao, T., 2004. Wastewater treatment performance of a filtration bio-reactor equipped with a mesh as a filter material. Water Res. 34 (17), 4143-4150.

Kuberkar, V.T., Davis, R.H., 2000. Modeling of fouling reduction by secondary membrane. J. Membr. Sci. 168 (1-2), 243-258.

Langé, K.P., Bellamy, W.D., Hendricks, D.W., Logsdon, G.S., 1986. Diatomaceous earth filtration of giardia cysts and other substances. JAWWA 76 (1), 76-84.

Ongerth, J.E., Hutton, P.E., 2001. Testing of diatomaceous filtration for removal of Cryptosporidium oocysts. JAWWA 93 (12), 54-63.

Seo, G.T., Moon, B.H., Lee, T.S., Lim, T.J., Kim, I.S., 2002. Non-woven fabric filter separation activated sludge reactor for domestic wastewater reclamation. Water Sci. Technol. 47 (1), 133-138.

Seo, G.T., Moon, B.H., Lee, T.S., Park, Y.M., Kim, S.H., 2007. Filtration characteristics of immersed coarse pore filters in an activated sludge system for domestic wastewater reclamation. Water Sci. Technol. 55 (1-2), 51-58.

Thurman, E.M., Malcolm, R.L., 1981. Preparative isolation of humic substances. Environ. Sci. Technol. 15 (5), 463-466.

Tian, J., Liang, H., Yang, Y., Tian, S., Li, G., 2008. Membrane absorption bioreactor (MABR) for treating slightly polluted surface water supplies: as compared to membrane bioreactor (MBR). J. Membr. Sci. 325 (1), 262-270.

Xu, B., Gao, N.Y., Sun, X.F., 2007. Characteristics of organic material in Huangpu River and treatability with the $\mathrm{O}_{3}$-BAC process. Sep. Purif. Technol. 57, 348-355.

Ye, M., Zhang, H., Wei, Q., Lei, H., Yang, F., Zhang, X., 2006. Study on the suitable thickness of a PAC-precoated dynamic membrane coupled with a bioreactor for municipal wastewater treatment. Desalination 194 (1-3), 108-120.

Zhao, Y., Cao, D., Liu, L., Jin, W., 2006. Municipal wastewater treatment by moving-bed-biofilm reactor with diatomaceous earth as carriers. Water Environ. Res. 78 (4), 392-396. 